\title{
Complex mullarian duct abnormality in a young female: a theraputic dilemma
}

\author{
Mukta Agarwal*, Bhawana Tiwary, Prajnanika Gurung
}

Department of Obstetrics and Gynecology, AIIMS, Patna, Bihar, India

Received: 17 May 2017

Accepted: 17 June 2017

\section{*Correspondence:}

Dr. Mukta Agarwal,

E-mail: Agarwal_mukta2006@yahoo.co.in

Copyright: (C) the author(s), publisher and licensee Medip Academy. This is an open-access article distributed under the terms of the Creative Commons Attribution Non-Commercial License, which permits unrestricted non-commercial use, distribution, and reproduction in any medium, provided the original work is properly cited.

\begin{abstract}
Genital outflow tract obstruction is a rare cause of primary amenorrhoea. Cervical agenesis is a very rare condition often associated with atresia of vagina. Clinical diagnosis is usually difficult before surgery. Transverse vaginal septum or vaginal agenesis is also a rare condition that results from incomplete fusion between vaginal components of the mullerian ducts and urogenital sinus. If the septum is complete, the menstrual flow will be obstructed causing primary amenorrhoea. The septum is basically a membrane of fibrous connective tissue with both muscular and vascular components formed anywhere along the vagina during embryological development. Here we present a case of 18 year old female who presented with primary amenorrhea, cyclical lower abdominal pain and menouria since 5 years. There was no history of attainment of menarche. The clinical examination revealed a small, blind ending lower vagina with a tough transverse membrane separating the lower portion from the upper genital tract. The ultrasound examination revealed a normal size uterus with hematometra. The magnetic resonance imaging of pelvis confirmed the presence of hematometra and transverse vaginal septum. Transverse vaginal septum resection followed by abdomino-perineal cervicoplasty was done in this patient.
\end{abstract}

Keywords: Cervical agenesis, Menarche, Menuria, Primary amenorrhea, Transverse vaginal septum, Urogenital sinus

\section{INTRODUCTION}

Transverse vaginal septum is a rare congenital anomaly that results from incomplete fusion of the vaginal components of the Mullerian ducts and the urogenital sinus. The septum can vary in thickness and may be located anywhere along the vagina, although most are found at the junction of upper and mid-vagina. Clinical presentation depends on whether it is complete or partial. Cervical agenesis is a very rare condition often associated with atresia of vagina. Clinical diagnosis is usually difficult before surgery. With complete agenesis, menstrual blood accumulates and distends structures above it after puberty, resulting in hematocolpos and hematometra. Such patients usually present with cyclical lower abdominal pain with primary amenorrhea. Occasionally a lower abdominal mass (hematometra) is palpable. Imaging has an dispensible role in distinguishing transverse vaginal septum from the more common imperforate hymen and agenesis or severe hypoplasia of the cervix. ${ }^{1}$

\section{CASE REPORT}

An 18 years old female presented to the outpatient department of a tertiary care centre of Eastern India with history of primary amenorrhea and cyclical abdominal pain with menouria (which was confirmed by urine microscopy) since 5 years. The pain was localized to supra-pubic region, intermittent (once in a month) and 
colicky. There was no complaint of dyspareunia and she was sexually active for 3 years. She underwent some surgical procedure twice 5 years and 2 years back at private set-up but no surgical records were available. Her secondary sexual characters were well developed and general physical examination was normal. Her breasts were Tanner stage 5 . Her external genitalia were normal with normal distribution of axillary and pubic hairs.

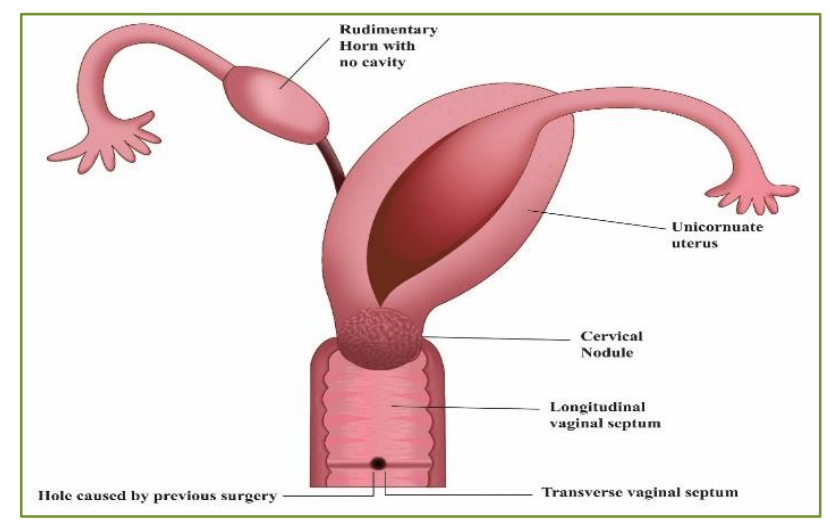

Figure 1: Pre-operative picture.

On per speculum examination, cervix was not visualized and a blind vaginal pouch of $3 \mathrm{cms}$ with a half centimeter dimple was seen. There was no bulging of hymen. On rectal examination, there was a bulge palpable? Hematometra. Ultrasound examination revealed normal size uterus with mild collection in the endometrial cavity (hematometra) and normal bilateral ovaries. MRI pelvis was done which showed T1 iso intense and T2 hyper intense contents in the endometrial cavity with similar contents in endocervical canal. There was a thick septum about $3 \mathrm{~cm}$ away from the vaginal introitus completely separating the lower $1 / 3^{\text {rd }}$ of the vagina from the upper portion. There was no obvious communication between uterus and urinary bladder. With these imaging reports, patient was posted for examination under anesthesia and septum resection. Transverse vaginal septum was resected which led to opening of a blind pouch. Cervix was not felt. Later the patient was posted for abdominoperineal cervicoplasty.

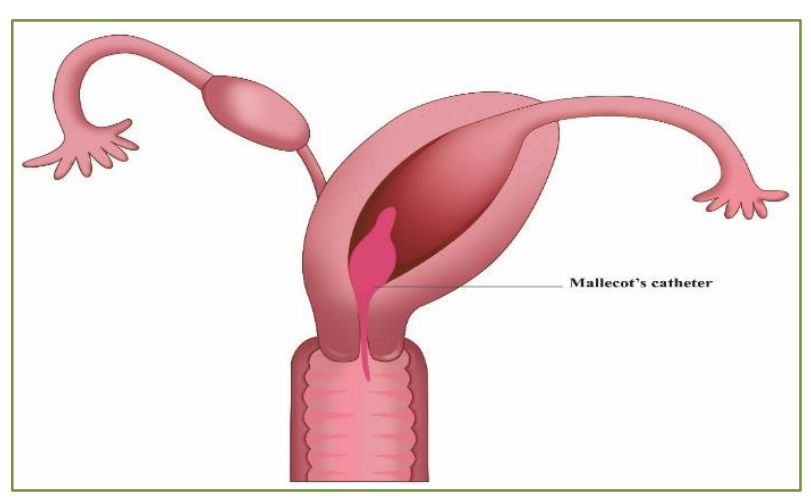

Figure 2: Post-operative picture.

\section{Intra-operative findings}

On Laprotomy, Unicornuate uterus with a rudimentary horn (non-communicating, no cavity) was found. Bladder at one point was densely adherent with uterus which was separated and repaired. Abdomino-perineal cervicoplasty was performed by dilating the cervix through a small vertical incision on anterior surface of uterus. Lower end of uterus is identified by passing a dilator through uterine incision and it was incised. vaginal vault was incised and sutured withanterior and posterior edges of uterine incision. Malecot's catheter was placed for maintaining the patency. Vaginal mould was given with surgicel. There was wound infection in the post-operative period which was managed by dressing and antibiotics and later resuturing of the abdominal wound was done. Patient was discharged on Sequential Estrogen and Progesterone regimen (Premarin $1.25 \mathrm{mg}$ for 2 months with progesterone overlap for last 10 days). Malecot's catheter was removed after 6 weeks. Patient resumed her menses and is on regular follow up.

\section{DISCUSSION}

Transverse vaginal septum is a defect of vertical fusion during embryogenesis of the vagina with an incidence of 1:30,000 to $1: 84,000$ women. Transverse vaginal septum is classified as class I anomaly by Digwani and Falcone classification system for vaginal anomalies. ${ }^{1}$ Embryologically, the upper two-third of the vagina develops from the Mullerian duct and the lower third of the vagina is formed from the ascending sinovaginal bulb which fuses with the mullerian duct. Transverse vaginal septum develops due to failure of resorption of the tissue between the vaginal plate, originating from the urogenital sinus and the caudal aspect of the fused mullerian ducts around the $5^{\text {th }}$ month of gestation. So, this septum divides the vagina into two segments, reducing its functional length and causing outlet tract obstruction. These septa are commonly located in the upper vagina ( $46 \%$ of cases) but can also be located in the mid $(40 \%)$ or lower $(14 \%)$ vagina. $^{1}$

Cervical agenesis is a congenital disorder of the female genital system that manifests itself in the absence of cervix, the connecting structure between the uterus and vagina. One mild form of condition in which cervix is present but deformed and non-functional are known as cervical atresia or cervical dysgenesis. ${ }^{2}$ Patients with cervical atresia or cervical dysgenesis. Patients with cervical agenesis typically present in early adolescence, around the time of menarche, with amenorrhea and cyclic pelvic pain caused by the obstruction of menstrual flow from the uterus. The diagnosis of cervical agenesis can be made by magnetic resonance imaging, which is used to determine the presence or absence of a cervix. Although MRI can detect the absence of a cervix (agenesis), it is unable to show cervical dysgenesis (where the cervix is present, but malformed). Ultrasound is a less reliable imaging study, but it is often the first choice by 
gynecologists to establish a diagnosis and can identify a hematometra secondary to cervical agenesis. ${ }^{3}$

A transverse vaginal septum is either perforate (incomplete) or imperforate (complete) and results from varying degrees of failure of resorption of the tissue between the vaginal plate and the caudal aspect of the fused Mullerian ducts. In the case of complete septum, patients commonly present with primary amenorrhea and cyclic pelvic pain. Incomplete septum may later present with dyspareunia and dysmenorrhoea. The membrane, when visible will be thick and pink and will not allow transillumination, unlike an imperforate hymen. If the patient has normal secondary sexual characteristics like development of breasts and pubic hair, ultrasonography or magnetic resonance imaging is indicated. And if the patient has normal uterus, an outflow tract obstruction should be considered. However, the vaginal septum could not be confirmed on ultrasound. The thick myometrial wall and milder distension of the uterine cavity, as compared with the thin and often imperceptible wall of the vagina aid in differentiating the uterus from the cervix. The lower uterine segment is funnel shaped as it is narrowed with hematometra in the absence of hematocolpos in cervical agenesis. MRI helps in depicting the pelvic anatomy and in determining the thickness of vaginal septum. ${ }^{4}$ Identification of cervix in MRI is crucial for differentiating a high transverse vaginal septum from congenital absence of the cervix.

In present case, we could find a unique combination of mullarian anomalies involving vagina (Transverse Vaginal Septum), cervix (cervical agenesis) and uterus (unicornuate uterus with non-communicating, noncavited horn). We could not find any class to assign in the present American Fertility Society (AFS) classification, but this anomaly can be assigned to class U IV b C2 V3 of newer consensus classification by ESHRE/ESGE. ${ }^{5,6}$ On reviewing the literature, we did not find any similar case reported. we could find one case report with univornuate uterus with cervival dysgenesis. ${ }^{5}$ In present literature review, we could find a similar case report with unicornuate uterus with rudimentary horn and cervical dysgenesis but in that case, vagina was patent. ${ }^{7}$ In present case, diagnosis was difficult, due to complex nature of anomaly, and MRI not revealing cervical agenesis or unicornuate uterus. In our case, surgery yield satisfactory result and menses were resumed. We did not excise the rudimentary horn, because, on incising the rudimentary horn, we did not find any cavity or endometrium.

\section{CONCLUSION}

In Conclusion, various complex Mullarian duct anomalies may exist with combined features of more than one class. Clinical diagnosis is usually difficult and MRI remains the investigation of choice. Early surgery offered to the patient may reduce patients suffering, help restore a patent outflow tract and may preserve fertility in some cases.

\section{ACKNOWLEDGMENTS}

Authors would like to thank Mr. Menajuddin Ansari, Artist, Modeller, Department of Anatomy for his contributions with figures.

Funding: No funding sources

Conflict of interest: None declared

Ethical approval: Not required

\section{REFERENCES}

1. Junqueira BL, Allen LM, Spitzer RF, Lucco KL, Babyn PS, Doria AS. Mullerian Duct Anomalies and Mimics in Children and Adolescents: Correlative Intraoperative Assessment with Clinical Imaging. Radiographics. 2009;29(4):1085-1103.

2. Lodi A. Clinical Statistics Clinical Contribution on the Obstetric and Gynecological Obstetric Vaginosis in Milan from 1906 to 1950. Ann Obstet Gine. 1951;73:1246.

3. Opoku BK, Djokoto R, Owusu-Bempah A, AmoAntwi K. Huge abdominal mass secondary to a transverse vaginal septum and cervical dysgenesis. Ghana Med J. 2011;45(4):174-6.

4. Troiano RN, McCarthy SM. Mullerian duct anomalies: imaging and clinical issues. Radiology. 2004;233(1):19-34.

5. Oppelt P, Renner SP, Brucker S, Strissel PL, Strick R, Oppelt PG et al. The VCUAM (Vagina Cervix Uterus Adnex-associated Malformation) Classification: a new classification for genital malformations. Fertili Steril. 2005;84(5):1493-7.

6. Grimbizis GF, Gordts S, Di Spiezio Sardo A, Brucker S, De Angelis C, Gergolet M et al. The ESHRE/ESGE consensus on the classification of female genital tract congenital anomalies. Human Reprod. 2013;28(8):2032-44.

7. Kumar S, Satija B, Wadhwa L. Complex mullerian duct anomaly in a young female with primary amenorrhoea, infertility, and chronic pelvic pain. J Hum Reprod Sci. 2012;5(3):295-7.

Cite this article as: Agarwal M, Tiwary B, Gurung P. Complex mullarian duct abnormality in a young female: a theraputic dilemma. Int J Reprod Contracept Obstet Gynecol 2017;6:3673-5. 